\title{
Removal of Potential Phosphorylation Sites does not Alter Creatine Transporter Response to PKC or Substrate Availability
}

\author{
Lucia Santacruz ${ }^{a}$ Marcus D. Darrabie Rajashree Mishrac Danny O. Jacobs $^{a, b}$ \\ aThe University of Texas Medical Branch, and the ${ }^{b}$ Institute for Translational Sciences, University of \\ Texas Medical Branch, Galveston, TX, 'Duke University Medical Center, Durham, NC, USA
}

\section{Key Words}

Energy metabolism $\cdot$ Cardiac metabolism $•$ Creatine $\cdot$ Membrane transport $\cdot$ Phosphorylation - Protein kinase C (PKC)

\begin{abstract}
Background: Creatine, Phosphocreatine, and creatine kinases, constitute an energy shuttle that links ATP production in mitochondria with cellular consumption sites. Myocytes and neurons cannot synthesize creatine and depend on uptake across the cell membrane by a specialized transporter to maintain intracellular creatine levels. Although recent studies have improved our understanding of creatine transport in cardiomyocytes, the structural elements underlying the creatine transporter protein regulation and the relevant intracellular signaling processes are unknown. Methods: The effects of pharmacological activation of kinases or phosphatases on creatine transport in cardiomyocytes in culture were evaluated. Putative phosphorylation sites in the creatine transporter protein were identified by bioinformatics analyses, and ablated using site-directed mutagenesis. Mutant transporter function and their responses to pharmacological PKC activation or changes in creatine availability in the extracellular environment, were evaluated. Results: PKC activation decreases creatine transport in cardiomyocytes in culture. Elimination of high probability potential phosphorylation sites did not abrogate responses to PKC activation or substrate availability. Conclusion: Modulation of creatine transport in cardiomyocytes is a complex process where phosphorylation at predicted sites in the creatine transporter protein does not significantly alter activity. Instead, nonclassical structural elements in the creatine transporter and/or interactions with regulatory subunits may modulate its activity.

Copyright (C) 2015 S. Karger AG, Basel
\end{abstract}

\section{Introduction}

Creatine ( $\mathrm{Cr}$ ) and Phosphocreatine (PCr) constitute an important metabolic energy reservoir system in tissues with fluctuating energy demands, such as skeletal and cardiac 
muscle. Together with creatine kinases (CKs), Cr and PCr link sites of ATP production within mitochondria to where ATP is consumed, i.e. the contractile machinery and ion pumps such as the $\mathrm{Na}^{+} / \mathrm{K}^{+}$ATPase and $\mathrm{Ca}^{2+}$ ATPases [1]. Myocytes and neurons cannot synthesize $\mathrm{Cr}$, and depend on transport across the cell membrane to maintain $\mathrm{Cr}$ at adequate levels within the cell. Cr transport is accomplished by a membrane protein, the creatine transporter (CrT), which belongs to the SLC6 gene family of transporters. Members of this family of proteins include the GABA (GAT1), serotonin (SERT), norepinephrine (NET), and dopamine (DAT) transporters. These closely related $\mathrm{Na}^{+} / \mathrm{Cl}^{-}$transporter proteins are regulated by PKC activation that decreases substrate uptake and increases transporter internalization [2].

Decreases in cardiomyocellular $\mathrm{Cr}$ and $\mathrm{PCr}$ levels are a well-documented finding in the failing heart and correlate with disease morbidity [3]. In skeletal muscle, $\mathrm{Cr}$ and $\mathrm{PCr}$ concentrations are altered by acute illness, such as systemic infection [4]. Inborn errors in the gene encoding the CrT protein cause intellectual disabilities, delayed speech development, and behavioral alterations similar to those described in autism [5].

Oral $\mathrm{Cr}$ supplementation is widely used by athletes as a legal ergogenic agent to improve performance. Additionally, there is evidence suggesting that $\mathrm{Cr}$ supplementation has beneficial effects in the context of neurodegenerative diseases and a protective effect during ischemic insults to the central nervous system has been reported [6, 7]. Given the role $\mathrm{Cr}$ plays in maintaining adequate energy reserves in metabolically active tissues, the reported benefits of oral $\mathrm{Cr}$ supplementation, and the observations indicating $\mathrm{Cr}$ levels in skeletal and cardiac muscle are affected by disease, it is important to understand how $\mathrm{Cr}$ transport is regulated during health and disease.

The molecular mechanisms regulating $\mathrm{Cr}$ transport are not well understood. In cardiac and skeletal myocytes $\mathrm{Cr}$ uptake is affected by the extracellular concentration of $\mathrm{Cr}$. Increases in extracellular $\mathrm{Cr}$ decrease $\mathrm{Cr}$ uptake, whereas decreases in $\mathrm{Cr}$ content increase $\mathrm{Cr}$ transport $[8,9]$ by changing the $\mathrm{V}_{\text {max }}$ of transport without significantly altering $\mathrm{K}_{\mathrm{m}}$. Recently, we [9] and others [10] have demonstrated that activation of AMPK, the cell's energy master regulator [11], modulates $\mathrm{Cr}$ transport in a tissue specific manner. In cardiomyocytes in culture, AMPK activation increases $\mathrm{V}_{\text {max }}$ of $\mathrm{Cr}$ transport, whereas AMPK activation in kidney cells in culture results in decreases $\mathrm{Cr}$ transport. In cardiomyocytes, these changes in $\mathrm{V}_{\max }$ correlate with decreases in the cell surface fraction of CrT protein, indicating that changes in the cell surface population are associated with the cellular responses to extracellular creatine availability. Experiments in Xenopus laevis oocytes expressing CrT suggest that transport activity may be regulated by SGK1 (serum and glucocorticoid inducible kinase I) in a mechanism involving PIKfyve and the formation of PI(3,5) $\mathrm{P}_{2}$ [12]. Pharmacological activation of PKC diminishes $\mathrm{Cr}$ transport in L6 muscle cells and Xenopus laevis oocytes expressing the CrT protein $[8,13]$. PKC isoforms are ubiquitously expressed, but its $\varepsilon$ and $\delta$ isoforms are prevalent in cardiac muscle. Both isoforms are active during ischemic preconditioning, with PKC having a protective role whereas the $\delta$ isoform has a detrimental effect. In chronic heart failure both isoforms are also active and appear to contribute to the development of cardiac hypertrophy $[14,15]$ and progressive heart failure [16].

In this study, we tested the hypothesis that changes in the phosphorylation of $\mathrm{S}$ and/or $\mathrm{T}$ amino acids within the CrT protein sequence underlie the transport modulation observed following PKC activation and changes in $\mathrm{Cr}$ availability. We report, for the first time, the results of a systematic study guided by bioinformatics, and designed to identify specific amino acids within the CrT that might influence its response to substrate availability and exposure to PKC. We also determined if other kinases or phosphatases besides PKC could affect $\mathrm{Cr}$ transport in cardiomyocytes.

\section{Materials and Methods}

cDNA Construction of CrT Mutants

The cDNA encoding the human CrT was a kind gift from Dr. Marc Caron (Duke University, Department of Cell Biology) and was subcloned into pBluescript KS vector (Stratagene, La Jolla, CA). Using polymerase 
chain reaction, a unique EcorI site followed by a Kozak sequence was introduced 5' to the initiation ATG. Using the same approach, the natural stop codon was removed and replaced with a unique XbaI site. Two $1 \mathrm{kB}$ cassettes encompassing the EcoRI -PstI fragment and the PstI-XbaI fragment were used as templates for site directed mutagenesis. Netphos 2.0, a neural network algorithm [17] was used to predict high probability consensus phosphorylation sites in the primary sequence of CrT protein (P48029). High scoring consensus sites within sequence segments predicted to have an intracellular disposition (selected segments connecting hydrophobic domains and the N- and C-termini, Table 1,) were subjected to site directed mutagenesis using the QuickChange mutagenesis system (Agilent, La Jolla, CA). Y residues were replaced with F, whereas S and $\mathrm{T}$ amino acids were replaced with $\mathrm{A}$. The EcorI-PstI or PstI-XbaI cassettes bearing the mutant sites were sequenced in their entirety to verify that only the intended nucleotide changes were introduced and swapped into the wild-type background and subcloned in the mammalian expression vector pcDNA 3.1B (Invitrogen, Carlsbad CA). Transfection of this construct results in expression of CrT protein bearing a $\mathrm{C}$-terminal Myc/His tag which does not alter CrT function [9]. As a negative control for expression, the cDNA encoding CrT was subcloned into pcDNA3.1(+) in reverse orientation with respect to the CMV promoter.

\section{Cell Culture, Transfection, and Expression}

HL-1 cells, an immortalized murine atrial cardiomyocyte cell line [18], were grown as previously described [9]. GripTite cells (Invitrogen, Carlsbad, CA), a variant of HEK 293 cells, were cultivated following the manufacturer's guidelines. CrT proteins were expressed in HL-1 or Griptite cells following transfection using Lipofectamine 2000 (Life Technologies, Grand Island, NY). Cr-depleted media was prepared as described [9]. The $\mathrm{Cr}$ concentration in $\mathrm{Cr}$-depleted media was $0.5-1 \mu \mathrm{M}$. Cr content in control media was $16.6 \mu \mathrm{M}$, which closely approximates the $\mathrm{Cr}$ concentrations measured in normal mice, rat and human sera [19]. Cr-supplemented media were prepared by adding the appropriate volume of sterile, freshly prepared $30 \mathrm{mM} \mathrm{Cr}$ solution in water to the $\mathrm{Cr}$-depleted media. This concentration approximates the circulating levels reported in humans $(0.5-1 \mathrm{mM})$ receiving Cr supplementation [20].

\section{Creatine Uptake and phosphorylation modulator assays}

$\mathrm{Cr}$ uptake assays were performed in HL-1 cells expressing the wild type or mutant CrT proteins as previously described (9). Briefly, 16 hours after transfection the cells were incubated for 48 hours in Cr-depleted or Cr-supplemented media. Assays were performed in triplicate. Protein concentration was determined using a bicinchonic acid (BCA) protein assay (Pierce Biotechnology, Rockford IL) with bovine serum albumin as a standard. In experiments using kinase or phosphatase agonists or inhibitors, HL-1 cell cultures were incubated for 30 minutes at $37^{\circ} \mathrm{C}$ in media supplemented with either $100 \mu \mathrm{M} \mathrm{C} 2$-ceramide, 10 nM Calyculin A, $10 \mu \mathrm{M}$ Compound C, $100 \mathrm{nM}$ Calphostin, or 100nM $\beta$-PMA. All modulators were dissolved in DMSO. Therefore, the control samples were $0.01 \% \mathrm{v} / \mathrm{v}$ DMSO in culture media. Modulators were purchased from EMD Millipore, (Billerica, MA). Unless otherwise indicated, uptake was performed with $15 \mu \mathrm{M} \mathrm{Cr}$ uptake buffer and supplemented with ${ }^{14} \mathrm{C}$-Creatine $(0.275 \mu \mathrm{Ci} / \mathrm{ml})$ as previously described [9].

\section{Kinetic and Statistical Analyses}

Reported data represents mean \pm standard error of the mean and were analyzed using the Student's t-test for independent samples. Probability values $\leq 0.05$ were considered significant. $\mathrm{V}_{\max }$ and $\mathrm{K}_{\mathrm{m}}$ values were determined as previously from Michaelis-Menten plots generated using curve-fitting software (SigmaPlot ver. 9.0, Chicago, IL) as previously described [9]. The data were analyzed using non-linear leastfit squares, and best-fit lines were plotted. Where indicated, ANOVA was performed, followed by use of the LSD post-hoc, pair-wise test for independent samples (STASTICA ver. 6.0, Tulsa, OK).

\section{Results}

Cr Transport in HL-1 cells is decreased by PKC activation

To examine the events regulating $\mathrm{Cr}$ transport in cardiomyocytes, we determined if pharmacological activation of major kinases or phosphatases affected Cr transport in HL-1 cardiomyocytes. HL-1 cells expressing CrT were grown in control media as well as in media- 
Fig. 1. Effects of pharmacological activation of major kinases and phosphatases on Cr transport HL-1 cells expressing the CrT protein where incubated the presence of media containing Calyculin A, $\beta$-PMA, Calphostin and Compound $\mathrm{C}$ as described in Materials and Methods. Cells treated with the PKC activator $\beta$-PMA $\left(^{*}\right)$, had significantly reduced Cr transport when compared with cells treated with the vehicle, $0.01 \%$ DMSO. $(\mathrm{n}=5$, ANOVA, Fisher LSD, $\mathrm{p}<0.05$ ).

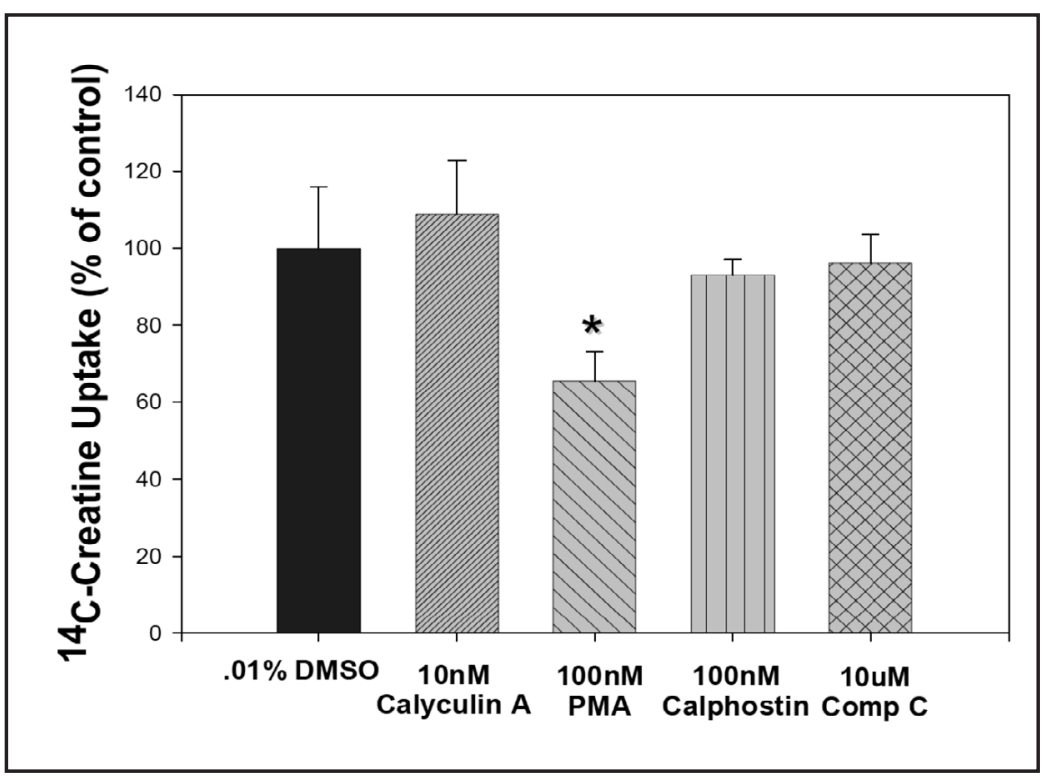

depleted of $\mathrm{Cr}$ or supplemented with $1 \mathrm{mM} \mathrm{Cr}$. The phosphorylation modulators tested were Calyculin A, an inhibitor of PP1a/PP2a; $\beta$-PMA, an activator PKC; Calphostin C, a PKC inhibitor; Compound C, a AMPK inhibitor; Genistein, a tyrosine kinase inhibitor; C2 Ceramide, a PP2a activator; and Forskolin, a PKA activator. Of the reagents tested, only incubation with 100nM $\beta$-PMA had a significant effect by decreasing Cr transport by approximately 35\% (Fig. 1).

To further characterize the effect of PKC activation on $\mathrm{Cr}$ transport, we determined the $\mathrm{V}_{\max }$ and $\mathrm{K}_{\mathrm{m}}$ of $\mathrm{Cr}$ transport following treatment of HL- 1 cells with $\beta$-PMA. CrT-myc transfected HL-1 cells were incubated in 100nM $\beta$-PMA prior to uptake assays performed in solutions containing increasing $\mathrm{Cr}$ concentrations $(5-305 \mu \mathrm{M})$ containing $\left[{ }^{14} \mathrm{C}\right]$-creatine. Control $\mathrm{HL}-1$ cells had a $\mathrm{K}_{\mathrm{m}}$ of $56.60 \pm 8.98 \mu \mathrm{M}$ and a $\mathrm{V}_{\text {max }}$ of $2.11 \pm 0.42 \mathrm{nmol} / \mathrm{mg}$ protein. Cr transport in $\beta$-PMA treated HL-1 cells had a $\mathrm{K}_{\mathrm{m}}$ of $55.80 \pm 12.00 \mu \mathrm{M}$ and a significant decrease in $\mathrm{V}_{\max }$ to $1.23 \pm 0.53 \mathrm{nmol} / \mathrm{mg}$ protein compared to the control.

Response of CrT phosphorylation site mutants to $\beta$-PMA and substrate availability

The effects of PKC activation on Cr transport function suggested that the phosphorylation of $\mathrm{S}$ and/or $\mathrm{T}$ in $\mathrm{CrT}$ could modulate changes in $\mathrm{Cr}$ uptake in response to $\beta$-PME, and, extracellular substrate availability. The NetPhos 2.0 neural network algorithm was used in combination with current topology models to predict intracellular phosphorylation consensus sites with high probability of being modified (Table 1). The consensus sites with the highest probability scores were found clustered at the beginning of the N-terminus (S5 and Y11) and the end of the C-terminus (T620, S623, and S625) of the CrT protein (Table 1 ), both predicted to be intracellular. Site-directed mutagenesis was used to replace $S$ or $\mathrm{T}$ amino acids with $\mathrm{A}$, and $\mathrm{Y}$ with $\mathrm{F}$. These conservative substitutions are not expected to disturb the structure and function of the protein beyond the functional effects attributable to the removal of a phosphate group. To study the possibility that multiple phosphorylation sites were required for the modulation by substrate availability, PKC activation, multisite constructs were also prepared. These constructs eliminated sites with the highest phosphorylation probability scores at C-terminus 4X (T618A, T620A, S623A, S625A), $\mathrm{N}$-terminus 3X (S5A, S12A, S15A) and 6X (S5A, Y11F, T618A, T620A, S623A, S625A), which ablated the highest-probability phosphorylation sites at the $\mathrm{N}$ and C-termini. This mutant also included Y11, a non-PKC-dependent phosphorylation candidate, but given its very highpredicted probability for phosphorylation, it was included in the construct.

The initial evaluation of expression and function of the mutant constructs was performed in GripTite cells. All mutant CrT proteins were functional, with transport that exhibited saturation kinetics similar to those observed in the wild-type transporter [9] 


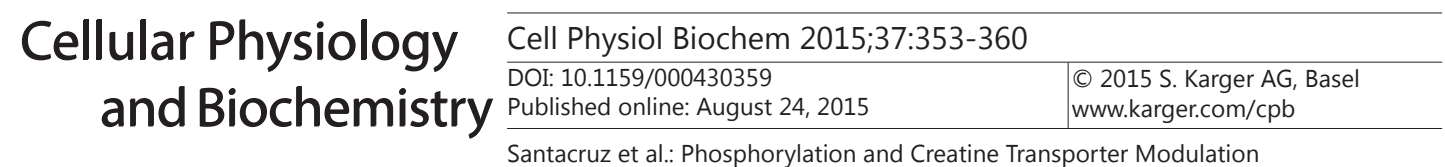

Table 1. NetPhos 2.0 neural network algorithm was used in combination with current topology models to predict intracellular phosphorylation consensus sites with high probability of being modified

\begin{tabular}{ccc}
\hline Amino acid & Consensus Sequence & Phosphorylation probability score \\
\hline S5 & MAKKSAENG & 0.945 \\
Y11 & ENGIYSVSG & 0.937 \\
S12 & NGIYSVSGD & 0.658 \\
S14 & IYSVSGDEK & 0.65 \\
T618 & RGLTTLTPV & 0.694 \\
T620 & LTTLTPVSE & 0.896 \\
S623 & LTPVSESSK & 0.946 \\
S625 & PVSESSKVV & 0.948 \\
\hline
\end{tabular}

Table 2. Cr uptake was measured in cultures expressing control, $\mathrm{CrT}$ and mutated $\mathrm{CrT}$ proteins where one or more consensus phosphorylation site was eliminated by conservative amino acid substitutions as described in experimental procedures. Uptake was measured in control culture media, media depleted of $\mathrm{Cr}$, media supplemented with 1 $\mathrm{mM} \mathrm{Cr}$ or normal media supplemented with $100 \mathrm{nM} \beta$-PMA. 3X, 4X and 6X are multisite mutant $\mathrm{CrT}$ proteins where the following amino acids were changed S5A/S12A/S15A, T618A/T620A/S623A/S625A and S5A/Y11F/T618A/T620A/S623A/S625A.Uptake values were normalized to control, and represent the average of a minimum of 3 independent assays, performed each in triplicate \pm SEM. All CrT mutants appeared statistically indistinguishable from the wild type $\operatorname{CrT}$ ( $p$ value was not significant)

\begin{tabular}{ccccc}
\hline CrT Protein & \multicolumn{4}{c}{ Relative Cr Uptake } \\
& Cr Supplemented Media & Control Media & Cr Depleted Media & $\beta$-PMA \\
\hline Control & $0.76 \pm 0.07$ & 1.0 & $2.07 \pm 0.12$ & $1.04 \pm 0.16$ \\
CrT & $4.46 \pm 0.51$ & $10.05 \pm 1.77$ & $14.55 \pm 1.45$ & $6.36 \pm 1.33$ \\
S5A & $4.46 \pm 0.34$ & $11.27 \pm 2.41$ & $14.85 \pm 1.58$ & $6.77 \pm 1.56$ \\
S12A & $6.24 \pm 0.73$ & $11.57 \pm 1.96$ & $15.95 \pm 1.36$ & $7.12 \pm 1.09$ \\
S14A & $4.87 \pm 0.50$ & $10.86 \pm 2.14$ & $15.77 \pm 2.77$ & $7.27 \pm 1.46$ \\
S623A & $3.46 \pm 0.11$ & $9.04 \pm 0.47$ & $12.02 \pm 0.30$ & $4.95 \pm 0.24$ \\
S625A & $4.62 \pm 0.11$ & $13.85 \pm 0.41$ & $24.60 \pm 1.35$ & $7.08 \pm 0.52$ \\
3X & $3.28 \pm 0.14$ & $6.73 \pm 1.91$ & $8.98 \pm 0.34$ & $4.46 \pm 0.61$ \\
4X & $4.46 \pm 0.23$ & $11.60 \pm 2.08$ & $16.55 \pm 1.86$ & $6.80 \pm 1.67$ \\
6X & $6.20 \pm 0.13$ & $12.22 \pm 1.47$ & $16.25 \pm 3.11$ & $9.42 \pm 3.61$ \\
\hline
\end{tabular}

(data not shown). The effect of incubation with $\beta$-PMA on the function of CrT mutants was measured in HL-1 cells expressing the single-site and multisite mutations. All single point and multiple-site mutant CrT proteins retained the wild-type CrT protein's ability to decrease their uptake by $30-40 \%$ after incubation with $\beta$-PMA (Table 2). An additional multisite mutant 9X (S5A, S12A, S14A, S256A T257A, T618A, T620A, S623A, S625A) that combined the $3 \mathrm{X}$ and $4 \mathrm{X}$ constructs in addition to residues S256 and T257, which are homologues to sites essential for PKC regulation of the norepinephrine transporter [21], was prepared. This construct also retained the capacity to respond to PKC activation. The CrT mutants' responses to Cr-depleted media, or media supplemented with $1 \mathrm{mM} \mathrm{Cr}$, was also quantified. All CrT phosphorylation mutants responded to alterations in substrate availability and PKC activation in the manner statistically indistinguishable from that of wild-type CrT, i.e., creatine uptake decreased when cells were exposed to media supplemented with $1 \mathrm{mM} \mathrm{Cr}$ or $\beta$-PMA, and increased when cells were incubated in Cr-depleted media (Table 2). 
These results indicate that none of the S/T (or Y) amino acids predicted to have a high probability of being phosphorylated play a major role, either alone or in combination, in the CrT's response to pharmacological PKC activation.

\section{Discussion}

Cells that cannot synthesize $\mathrm{Cr}$, such as neurons and skeletal or cardiomyocytes, depend on the $\mathrm{CrT}$ to maintain the intracellular Cr levels. Abnormalities in $\mathrm{Cr}$ transport adversely affect brain function, and decreases in cardiac CrT function contribute to the bioenergetics derangements that characterize the failing myocardium. However, very little is known about the signaling mechanisms responsible for the regulation of $\mathrm{Cr}$ uptake. In this study, we first examined the effect of pharmacological manipulation of kinases on CrT function in cardiomyocytes in culture. Consistent with previous studies of L6 myocytes [8] and Xenopus oocytes expressing CrT protein [13], pharmacologic PKC activation by the phorbolester $\beta$-PMA reduced $\mathrm{Cr}$ transport $\mathrm{V}_{\max }$ for $\mathrm{Cr}$ transport. This reduction in $\mathrm{Cr}$ transport was observed in HL-1 cells grown in all-Cr media concentrations. These observations suggest that $\mathrm{S}$ and/or $\mathrm{T}$ residues in the CrT protein are the target of phosphorylation by $\mathrm{PKC}$ isoform(s). We thus used site directed mutagenesis to eliminate high probability PKC phosphorylation sites individually, or in incremental groups. These mutations did not affect $\mathrm{Cr}$ transport, and furthermore, both the individual and multisite CrT mutant proteins responded to PKC activation and substrate availability in a manner equivalent to the wild type CrT.

A reduction in transport has also been reported after PKC activation in other closely related $\mathrm{Na}^{+} / \mathrm{Cl}^{-}$transporters, including GAT1, SERT, NET, and DAT. In these transporters, there is an increase in phosphorylation of the transporter proteins that correlates with decreased substrate uptake and increased rates in transporter internalization [2]. In the case of the NET protein, amino acids T258 and S259 are required for the internalization following PKC activation [21, 22]. Netphos 2.0 analysis of NET protein sequence, assigns a moderate phosphorylation probability score to T258 (0.765), whereas S259 has a low score (0.377). The equivalent amino acids in the CrT protein, S256 and T257, have low probability scores ( 0.253 and 0.339 respectively). Simultaneous elimination of the equivalent residues in the CrT protein (S256A and T257A) on their own (data not shown), or as part of multisite 9X CrT mutant had no effect on the response to PKC activation. A similar result was reported following the elimination of the equivalent sites in the DAT protein, the mutant DAT protein retained wild type responses to PKC activation [23]. Further studies identified the segment encompassed by residues 587-596 at the C-terminus of DAT as a non-classical endocytic signal required for PKC mediated internalization [24]. This sequence is conserved in other transporters of the SLC6 transporter family, but it is not present in CrT.

Ubiquitylation of multiple lysine residues at the N-terminus of DAT is required for internalization of DAT following PKC activation $[25,26]$. These lysine residues, although conserved in other neurotransmitter transporters, are also not present in CrT protein. Our results show that $\mathrm{Cr}$ transport responds similarly to other members of the SLC6 transporter family to PKC activation (by a reduction in $\mathrm{V}_{\max }$ ). However, the structural elements mediating the response of CrT may be different from those found in other SLC6 transporters. Although conservative replacement of $\mathrm{S}$ and $\mathrm{T}$ residues within predicted high-probability phosphorylation consensus sites did not affect the capacity of the CrT to be modulated by PKC activation, the results presented here do not rule out that modulation by PKC rely on CrT's S/T residues that were not analyzed in this study. It may also be possible that a more complicated mode of regulation exists, whereby one or more unidentified residues interact to regulate transport in response to substrate availability and activation/inhibition of S/T kinases.

Modulation by substrate and PKC could require interaction(s) with a presently unidentified intracellular partner protein(s), which could, in turn, be the target(s) of PKC phosphorylation. Changes in the phosphorylation state of these unidentified protein(s) could 
alter the stability or membrane insertion/retrieval rate for the CrT protein resulting in the observed changes in $V_{\text {max. }}$ The presence of different intracellular partners in different tissues could underline the tissue specific differences in $\mathrm{Cr}$ transport that are reported in response to AMPK activation in cardiac and renal cells [27]. Given that $\mathrm{Cr}$ transport regulation appears to be tissue specific, CrT protein could also be modulated by tissue specific kinases that are not expressed in HL-1 cells. Therefore, residues that do not appear to be necessary for modulation in cardiomyocytes may well be relevant for the modulation of $\mathrm{Cr}$ transport in other organs or tissues such as the brain and kidneys.

This is the first report of a systematic analysis of potential phosphorylation sites on the CrT protein of any species. Our results, exclude $\mathrm{S}$, $\mathrm{T}$ and $\mathrm{Y}$ residues with the highest predicted phosphorylation scores as required for the modulation of $\mathrm{CrT}$ function by substrate availability and PKC, and suggest that the mechanism(s), and CrT protein structural motifs regulating the responses to substrate availability and PKC activation may be different from those identified in other members of the SLC6 family of membrane proteins.

The identification of residues important in substrate recognition in CrT [28] provides a better understanding of the structural elements involved in the Cr permeation pathway. The reports of high-resolution structures of a prokaryotic homologue of the SLC6 proteins, the LeuT $\mathrm{Aa}_{\mathrm{Aa}}$ transporter [29], and more recently of the fruit fly DAT [30] have identified the binding pockets for $\mathrm{Cl}^{-}$and $\mathrm{Na}^{+}$ions required for substrate transport. Additionally, the functional role of post-translational modifications such as glycosylation, intramolecular disulfide bonds, and phosphorylation sites at the $\mathrm{C}$ terminus of DAT is also better understood. Whereas, as a member of the SL6A transporter family, CrT shares many basic structural features with these transporters, its functional modulation appears to differ from that of other SLC6 transporters. Elucidation of the structural basis for CrT regulation merits further study because of its importance to the health of certain human tissues.

\section{Acknowledgements}

We gratefully acknowledge Zhefeng Zhao, and Lauren E. Goers assistance with initial experiments, Eric M. Toloza for statistical analysis and discussion of preliminary data, and Quique Toloza for assistance with manuscript preparation.

\section{Disclosure Statement}

This work was funded by the Department of Surgery, Duke University Medical Center, and the University of Texas, Medical Branch, Galveston. The authors have no conflicts of interest to disclose.

\section{References}

1 Wyss M, Kaddurah-Daouk R: Creatine and creatinine metabolism. Physiol Rev 2000;80:1107-1213.

- Kristensen AS, Andersen J, Jorgensen TN, Sorensen L, Eriksen J, Loland CJ, Stromgaard K, Gether U: Slc6 neurotransmitter transporters: Structure, function, and regulation. Pharmacol Rev 2011;63:585-640. Neubauer S: The failing heart--an engine out of fuel. N Engl J Med 2007;356:1140-1151.

4 Lara TM, Wong MS, Rounds J, Robinson MK, Wilmore DW, Jacobs DO: Skeletal muscle phosphocreatine depletion depresses myocellular energy status during sepsis. Arch Surg 1998;133:1316-1321.

5 Stockler S, Schutz PW, Salomons GS: Cerebral creatine deficiency syndromes: Clinical aspects, treatment and pathophysiology. Subcell Biochem 2007;46:149-166.

-6 Prass K, Royl G, Lindauer U, Freyer D, Megow D, Dirnagl U, Stockler-Ipsiroglu G, Wallimann T, Priller J: Improved reperfusion and neuroprotection by creatine in a mouse model of stroke. J Cereb Blood Flow Metab 2007;27:452-459.

7 Perasso L, Spallarossa P, Gandolfo C, Ruggeri P, Balestrino M: Therapeutic use of creatine in brain or heart ischemia: Available data and future perspectives. Med Res Rev 2013;33:336-363. 


\section{Cellular Physiology Cell Physiol Biochem 2015;37:353-360 \begin{tabular}{l|l|l|}
\hline DOI: 10.1159/000430359 2015 S. Karger AG, Basel \\
\hline
\end{tabular}

8 Loike JD, Zalutsky DL, Kaback E, Miranda AF, Silverstein SC: Extracellular creatine regulates creatine transport in rat and human muscle cells. Proc Natl Acad Sci U S A 1988;85:807-811.

-9 Darrabie MD, Arciniegas AJL, Mishra R, Bowles DE, Jacobs DO, Santacruz L: Ampk and substrate availability regulate creatine transport in cultured cardiomyocytes. Am J Physiol Endocrinol Metabol 2011;300:E870-E876.

10 Li H, Thali R, Smolak C, Gong F, Alzamora R, Wallimann T, Scholz R, Pastor-Soler N, Neumann D, Hallows K: Regulation of the creatine transporter by amp-activated protein kinase in kidney epithelial cells. Am J Physiol Renal Physiol 2010;299:F167-177.

11 Hardie DG, Ross FA, Hawley SA: Ampk: A nutrient and energy sensor that maintains energy homeostasis. Nat Rev Mol Cell Biol 2012;13:251-262.

12 Strutz-Seebohm N, Shojaiefard M, Christie D, Tavare J, Seebohm G, Lang F: Pikfyve in the sgk1 mediated regulation of the creatine transporter slc6a8. Cell Physiol Biochem 2007;20:729-734.

13 Dai W, Vinnakota S, Qian X, Kunze D, Sarkar H: Molecular characterization of the human crt-1 creatine transporter expressed in xenopus oocytes. Arch Biochem Biophys 1999;361:75-84.

14 Duquesnes N, Lezoualc'h F, Crozatier B: Pkc-delta and pkc-epsilon: Foes of the same family or strangers? J Mol Cell Cardiol 2011;51:665-673.

15 Mochly-Rosen D, Das K, Grimes KV: Protein kinase c, an elusive therapeutic target? Nat Rev Drug Discov 2012;11:937-957.

16 Ferreira JC, Brum PC, Mochly-Rosen D: Betaiipkc and epsilonpkc isozymes as potential pharmacological targets in cardiac hypertrophy and heart failure. J Mol Cell Cardiol 2011;51:479-484.

17 Blom N, Gammeltoft S, Brunak S: Sequence and structure-based prediction of eukaryotic protein phosphorylation sites. J Mol Biol 1999;294:1351-1362.

18 White SM, Constantin PE, Claycomb WC: Cardiac physiology at the cellular level: Use of cultured hl-1 cardiomyocytes for studies of cardiac muscle cell structure and function. Am J Physiol Heart Circ Physiol 2004;286:H823-829.

19 Yasuhara M, Fujita S, Arisue K, Kohda K, Hayashi C: A new enzymatic method to determine creatine. Clin Chim Acta 1982;122:181-188.

20 Persky AM, Muller M, Derendorf H, Grant M, Brazeau GA, Hochhaus G: Single- and multiple-dose pharmacokinetics of oral creatine. J Clin Pharmacol 2003;43:29-37.

21 Jayanthi LD, Annamalai B, Samuvel DJ, Gether U, Ramamoorthy S: Phosphorylation of the norepinephrine transporter at threonine 258 and serine 259 is linked to protein kinase c-mediated transporter internalization. J Biol Chem 2006;281:23326-23340.

22 Jayanthi LD, Samuvel DJ, Ramamoorthy S: Regulated internalization and phosphorylation of the native norepinephrine transporter in response to phorbol esters. Evidence for localization in lipid rafts and lipid raft-mediated internalization. J Biol Chem 2004;279:19315-19326.

23 Granas C, Ferrer J, Loland CJ, Javitch JA, Gether U: N-terminal truncation of the dopamine transporter abolishes phorbol ester- and substance p receptor-stimulated phosphorylation without impairing transporter internalization. J Biol Chem 2003;278:4990-5000.

-24 Holton KL, Loder MK, Melikian HE: Nonclassical, distinct endocytic signals dictate constitutive and pkcregulated neurotransmitter transporter internalization. Nat Neurosci 2005;8:881-888.

-25 Miranda M, Wu CC, Sorkina T, Korstjens DR, Sorkin A: Enhanced ubiquitylation and accelerated degradation of the dopamine transporter mediated by protein kinase c. J Biol Chem 2005;280:35617-35624.

26 Miranda M, Dionne KR, Sorkina T, Sorkin A: Three ubiquitin conjugation sites in the amino terminus of the dopamine transporter mediate protein kinase c-dependent endocytosis of the transporter. Mol Biol Cell 2007;18:313-323.

27 Li H, Thali RF, Smolak C, Gong F, Alzamora R, Wallimann T, Scholz R, Pastor-Soler NM, Neumann D, Hallows KR: Regulation of the creatine transporter by amp-activated protein kinase in kidney epithelial cells. Am J Physiol Renal Physiol 2010;299:F167-177.

28 Dodd JR, Christie DL: Selective amino acid substitutions convert the creatine transporter to a gammaaminobutyric acid transporter. J Biol Chem 2007;282:15528-15533.

29 Yamashita A, Singh SK, Kawate T, Jin Y, Gouaux E: Crystal structure of a bacterial homologue of na+/cl-dependent neurotransmitter transporters. Nature 2005;437:215-223.

-30 Penmatsa A, Wang KH, Gouaux E: X-ray structure of dopamine transporter elucidates antidepressant mechanism. Nature 2013;503:85-90. 